\title{
Reef Reservoir Identification by Wavelet Decomposition and Reconstruction: A Case Study from Yuanba Gas Field in China
}

\author{
Bingjie $\mathrm{CHENG}^{1,2,3}$, Tianji XU ${ }^{4}$, Benedict ROBBINS ${ }^{5}$, \\ and ZhongMing SHEN ${ }^{1}$
}

${ }^{1}$ State Key Laboratory of Oil and Gas Reservoir Geology and Exploitation, Chengdu University of Technology, Chengdu, China; e-mail: chengbingjie09@cdut.cn

${ }^{2}$ Key Laboratory of Earth Exploration and Information Technology of Ministry of Education, Chengdu University of Technology, Chengdu, China

${ }^{3}$ Meteorological Information and Signal Processing,

Key Laboratory of Sichuan Higher Education Institutes, Chengdu University of Information Technology, Chengdu, China

${ }^{4} 3^{\text {rd }}$ Geophysical Institute, Exploration and Production Institute,

Southwest Oil and Gas Company, SINOPEC, Chengdu, China

${ }^{5}$ Fugro Aperio, Fugro Onshore Geotechnics, Wallingford, Oxfordshire, UK

\section{Abstract}

The organic reef is a special type of carbonate reservoir which always dominates the spatial distribution, reserves and accumulations of natural gas. However, it is difficult to determine the organic reef's internal structure and gas reservoirs due to numerous adverse factors such as the low resolution of seismic data, depth of burial, strong anisotropy, irregular spatial distribution and complex internal structure. A case study of wavelet decomposition and reconstruction technology applied to elucidate the features of organic reef reservoirs in the Changxing formation from Yuanba gas field shows that the seismic record reconstructed by high frequency signal can adequately describe the internal properties of

Ownership: Institute of Geophysics, Polish Academy of Sciences;

(C) 2015 Cheng et al. This is an open access article distributed under the Creative Commons Attribution-NonCommercial-NoDerivs license,

http://creativecommons.org/licenses/by-nc-nd/3.0/. 
organic reef reservoirs. Furthermore, the root mean square amplitude ratio of both low and high frequency data obtained from the reconstructed seismic data clearly show spatial distribution of gas and water in reef reservoirs.

Key words: seismic signal, organic reef, wavelet decomposition and reconstruction, hydrocarbon detection, reef reservoir identification.

\section{INTRODUCTION}

Marine carbonate reservoirs are widely distributed in China. However, these carbonate reservoirs are deeply buried, and there is strong vertical and horizontal heterogeneity, which contribute to increased difficulty in hydrocarbon detection. Reef gas reservoirs have been an important domain for gas exploration since the Yuanba gas field was discovered in the Sichuan basin; the Yuanba gas field shows huge potential as a prospective carbonate reef area. The growth scale and distribution of reef reservoirs are mainly controlled by carbonate sedimentary facies in the Changxing formation in Yuanba gas field (Ma et al. 2007, Bi et al. 2007). The identification of reef reservoirs is challenging, and some key problems remain to be solved, such as distinguishing water from gas, identifying the thickness of slim /fine layers, and improving accuracy in reservoir recognition.

In the reef reservoirs of Changxing formation in Yuanba gas field, the reef body is generally composed of reef base, reef core, and reef cap (Cai 2011). Organic reef is a special type of carbonate rock formation which has unique characteristics in terms seismic response. The seismic records show dome-shaped reflections from the outside reef, strong reflections or draping structure reflections from the reef top, discontinuous chaotic or nearly blank reflections from the inner reef, low elevation reflections from the reef bottom, and onlap reflections from the wings of the reef (Xiong et al. 2009, Hu et al. 2010). All of these characters aid in the identification of reef shape, and accurate location of the reef reservoir. However, it is difficult to clearly describe the detailed characteristics of the internal reef reservoirs due to some adverse factors, such as irregular spatial distribution, deep burial, low resolution seismic responses, strong heterogeneity, and anisotropy, complex internal structure and small physical differences between country rock and reservoirs.

For hydrocarbon detection, many geophysicists are optimistic about the use of the time-frequent seismic signal, which probes the response characteristics in both time and frequency domains (Castagna et al. 2003, Cohen 1995). However, most of their search has focused on the frequency, energy, amplitude, and attenuation properties ascertained through time-frequency analysis to obtain the low-frequency shallows and high-frequency attenuation of the gas reservoirs rather than to reconstruct seismograms in different 
frequencies (Burnett et al. 2003, Reine et al. 2009, Xu et al. 2011, Xue et al. 2013).

The technique of wavelet decomposition and reconstruction can adaptively decompose a seismic trace into a series of wavelets of different frequency, amplitude, and energy. Since these wavelets' attributes are closely related to geologic features and the properties of reservoirs, the method then reconstructs the atoms in terms of the information associated with the gas reservoirs, with certain targeted objectives in mind, and a new seismic trace can be reconstructed with a selected subset of wavelets, which is found to be highly informative for seismic data interpretation and reservoir characterization (An 2006).

\section{METHODS AND NUMERICAL MODELING}

\subsection{The theory of seismic wavelet decomposition and reconstruction}

Presently, many mathematic methods (such as Fourier transform, wavelet transform, S-transform, and Matching Pursuit) have been proposed to carry out the seismic wavelet decomposition and reconstruction techniques (Partyka et al. 1999, Battista et al. 2007, Zhang 2008, Sinha et al. 2009, Wang 2010, Zhang and $\mathrm{Lu} 2010$, Lu and Li 2013). In recent years, the method of Matching Pursuit was developed and widely applied in atom decomposition theory.

Matching Pursuit adaptively decomposes a seismic trace into a series of constituent wavelets (Mallat and Zhang 1993, Wang 2007). Each of these wavelets, selected from a dictionary consisting of a large number of wavelets, also called atoms, has an optimal correlation coefficient with the trace.

When considering the digital signal in atomic decomposition theory, the seismic trace can be decomposed to a series of wavelets with different dynamic characters, and the seismic trace can be reconstructed by simple linear super imposition of these wavelets. Xu et al.'s (2010) research outlines that if the original seismic trace $f(t)$ is decomposed $N$ times by the wavelet $M(t)$, then:

$$
f(t)=\sum_{n=0}^{N-1} A_{n} M_{n}(t)+E^{(N)} f,
$$

where $A_{n}$ is the amplitude of the $n$th wavelet $M_{n}(t), E^{(N)} f$ is residual error, when $n=0$ ( $n$th wavelet), $E^{(N)} f=f$.

The result of the seismic trace decomposition and reconstruction is highly correlated to wavelet choice; thus, it is very important to choose suitable wavelets. In this paper, we employ Morlet wavelets as atoms in wavelet decomposition and reconstruction because it is appropriate for seismic waves with energy attenuation and velocity dispersion (Morlet et al. 1982a, b). The Morlet wavelet has reliable time-frequency resolution and can match the 
signal to be analyzed furthest (Goupillaud et al. 1984, Gao et al. 1996); therefore, it has been widely used for wavelet transform in seismic data analysis (Grubb and Walden 1997, Farge 1992). Liu and Marfurt (2005) proposed a Matching Pursuit decomposition using Morlet wavelets. In this paper, we use a similar process, but develop a decomposition and reconstruction method based on Morlet wavelets.

Morlet et al.'s (1982a,b) research established Eqs. 2 and 3 for time domain and frequency domain wavelets and are still being currently used (Liu and Marfurt 2005):

$$
\begin{aligned}
& M(t)=\exp \left(-t^{2} \omega_{m}^{2} \cdot \ln 2 / k\right) \cdot \exp \left(i 2 \pi \omega_{m} t\right), \\
& M(\omega)=\frac{\sqrt{\pi / \ln 2}}{\omega_{m}} \cdot \exp \left(-k \cdot \frac{\pi^{2}\left(\omega-\omega_{m}\right)^{2}}{\ln 2 \cdot \omega_{m}^{2}}\right),
\end{aligned}
$$

where $\omega$ is the frequency, $\omega_{m}$ is the average frequency or dominant frequency, $k$ is a constant which acts on the Gussian part of the wavelet function to modulate the wave shape to obtain the best seismic wavelet.

In frequency or time domains, using Eqs. 2 or 3 to iteratively calculate Eq. 1, we can decompose the seismic trace $f(t)$ into a wavelet function library formed by several different Morlet wavelet functions. By using the linear combination of different Morlet wavelet functions in the wavelet library, the reconstructed seismic trace $f^{\prime}(t)$ is:

$$
f^{\prime}(t)=\sum_{m=0}^{M-1} A_{m} M_{m}(t), \quad M \leq N,
$$

where $N$ is the number of different morlet wavelet functions of original seismic trace $f(t), M$ is the number of different Morlet wavelet functions of reconstructed seismic trace $f^{\prime}(t) . M$ is less than $N$ and the closer the $M$ matches $N$, the closer the reconstructed seismic trace $f^{\prime}(t)$ matches the original seismic trace $f(t)$. When $M=N, f^{\prime}(t)=f(t)$.

During the iteration for wavelet decomposition, when the iterating times are enough to make the residual error $E^{(\Lambda)} f=0$, the reconstructed seismic trace $f^{\prime}(t)$ of all wavelet functions in the wavelet library equals the original seismic trace $f(t)$. If we ignore the residual errors produced in the process of Morlet wavelet decomposition and the linear summation of all Morlet wavelet functions, then $f^{\prime}(t) \approx f(t)$. However, we need also to consider the computational efficiency during real seismic trace decomposition; thus, it can always meet the requirment that $E^{(N)} f$ is small enough. Notably, in generalized cases, associated processing time and economic value are very important factors in terms of practical requirements. When $E^{(N)} f$ is small enough, the method of wavelet decomposition will cease. 


\subsection{Numerical modeling}

To illustrate the effectiveness of seismic wavelet decomposition and reconstruction methods for hydrocarbon detection, we produce a model to simulate the seismic response based on Hudson's theory (Hudson 1980, 1981, 1988; Hudson et al. 1996). The reservoirs in Yuanba gas field are porefractured reservoirs which are characterized by extremely low porosity, low permeability, and high-angle fractures. Primarily, there are vertical fractures distributing in the target interval (Hu et al. 2010, Chen 2011). The simplest effective model of a formation containing vertical fractures is horizontal transverse isotropy (HTI). For models with penny-shaped cracks, anisotropic coefficients, and weaknesses are expressed by the micro-structural parameters using the theories of Hudson (Hudson 1981, 1988; Hudson et al. 1996) and Thomsen (Thomsen 1986, 1995). Here, we use Hudson's model to calculate the elastic stiffness of anisotropic model, and use the expressions of fracture anisotropic parameters derived from the HTI model (Bakulin et al. 2000) to calculate the anisotropic parameters, which can be expressed as:

$$
\varepsilon=-\frac{8 e}{3}, \quad \delta=-\frac{8 e}{3}\left[1+\frac{g(1-2 g)}{(3-2 g)(1-g)}\right], \quad \gamma=-\frac{8 e}{3(3-2 g)},
$$

where $e=\mathrm{Na}^{3} / V$ is defined as the fracture density, and $V$ denotes the volume, $a$ is the fracture radius, $g=V_{S}^{2} / V_{P}^{2}$ is the square of $S$-wave to $P$-wave velocity ratio. The relationship between the fracture density $e$ and the aspect ratio $r$ can be obtained by volume percent $\xi=4 \pi r e / 3$.

The dimensionless parameters are normal $\Delta N$ and tangential $\Delta T$ weaknesses (Bakulin and Molotkov 1998), which can be calculated by the following equation:

$$
\Delta N=\frac{4 e}{3 g(1-g)}, \quad \Delta T=\frac{16 e}{3(3-2 g)} .
$$

The design of the model is based on the seismic data and reservoir logging parameters of the Yuanba Gas Field in Sichuan Basin, Southwest China. The geological models include six formations, where layers (7) and (8) are the gas-saturated carbonate and water-saturated carbonate, respectively (Fig. 1). The parameters of each layer are shown in Tables 1 and 2. Table 3 presents the fracture and anisotropy parameters calculated with the given fracture intensity. The formation thicknesses are $100 \mathrm{~m}$. We use a point resource to obtain the synthetic seismogram, whose dominant frequency is $25 \mathrm{~Hz}$ without any added noise.

Figure $2 \mathrm{a}$ shows the forward modeling seismogram of the fractured model in Fig. 1. The synthetic seismogram is obtained by the full-wave forward modeling of finite difference. The event (about $0.3 \mathrm{~s}$ ) is noticeably 


\begin{tabular}{|c|c|c|c|c|}
\hline \multicolumn{5}{|l|}{ (1) } \\
\hline \multicolumn{5}{|l|}{ (2) } \\
\hline \multicolumn{5}{|l|}{ (3) } \\
\hline (4) & 0.828 & (4) & o 8 orater & (4) \\
\hline \multicolumn{5}{|l|}{ (5) } \\
\hline (6) & & & & \\
\hline
\end{tabular}

Fig. 1. A gas-saturated and water-saturated carbonate geological model.

Table 1

Rock properties for the geological model

\begin{tabular}{|c|c|c|c|}
\hline Layer number & $\begin{array}{c}V_{p} \\
{\left[\mathrm{~m} \cdot \mathrm{s}^{-1}\right]}\end{array}$ & $\begin{array}{c}V_{s} \\
{\left[\mathrm{~m} \cdot \mathrm{s}^{-1}\right]}\end{array}$ & $\begin{array}{c}\rho \\
{\left[\mathrm{g} \cdot \mathrm{cm}^{-3}\right]}\end{array}$ \\
\hline (1) & 3945 & 2650 & 2.48 \\
(2) & 4300 & 2487 & 2.50 \\
(3) & 4540 & 2949 & 2.65 \\
(4) & 4804 & 3081 & 2.65 \\
(5) & 5340 & 2949 & 2.75 \\
(6) & 5750 & 3358 & 2.71 \\
\hline
\end{tabular}

Explanations: $V_{p}-P$-wave velocity, $V_{s}-S$-wave velocity, $\rho-$ density.

Table 2

Rock properties for the fracture layer

\begin{tabular}{|c|l|l|l|l|l|}
\hline $\begin{array}{c}\text { Layer } \\
\text { number }\end{array}$ & $\begin{array}{c}\text { Stratum } \\
\text { materials }\end{array}$ & $\begin{array}{c}V_{p} \\
{\left[\mathrm{~m} \cdot \mathrm{s}^{-1}\right]}\end{array}$ & $\begin{array}{c}V_{s} \\
{\left[\mathrm{~m} \cdot \mathrm{s}^{-1}\right]}\end{array}$ & $\begin{array}{c}\rho \\
{\left[\mathrm{g} \cdot \mathrm{cm}^{-3}\right]}\end{array}$ & $\begin{array}{c}\Phi \\
{[\%]}\end{array}$ \\
\hline $\begin{array}{c}(7)(8) \\
(7)\end{array}$ & Carbonate rock & 4.517 & 2.937 & 2.57 & 6.0 \\
(8) & Wixed gas & 0.7 & & 0.00089 & \\
\hline
\end{tabular}

Explanation: $\Phi$ is the porosity.

Table 3

The fracture and anisotropic properties of the gassy and hydrous layers

\begin{tabular}{|c|c|c|c|c|c|c|c|c|}
\hline \multirow{2}{*}{$\begin{array}{c}\text { Layer } \\
\text { number }\end{array}$} & \multicolumn{4}{|c|}{ Fracture parameters } & \multicolumn{3}{c|}{ Anisotropic parameters } \\
\cline { 2 - 9 } & $E\left[\mathrm{~m}^{-3}\right]$ & $r$ & $\Delta T$ & $\Delta N$ & $\theta\left[{ }^{\circ}\right]$ & $\varepsilon$ & $\delta$ & $\gamma$ \\
\hline (7) 8 & 0.02 & 0.01 & 0.05 & 0.11 & 30 & -0.05 & -0.05 & -0.02 \\
\hline
\end{tabular}

Explanation: $\theta$ is the obliquity. 


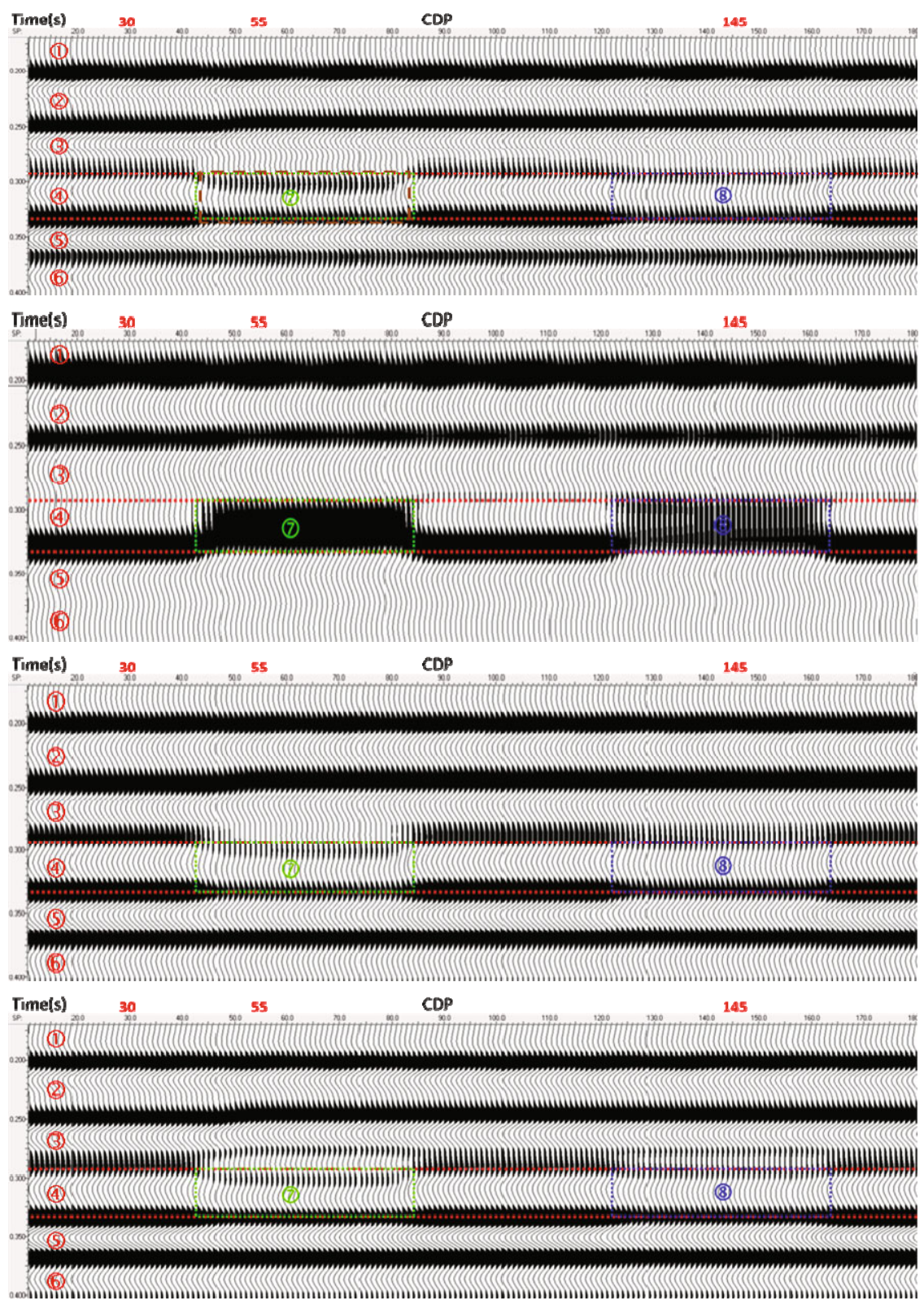

Fig. 2. Forward modeling and reconstructed seismic signal: (a) zero-offset synthetic seismogram of the geological model, (b) signal reconstruction at low frequency (from 5 to $10 \mathrm{~Hz}$ ), (c) signal reconstruction at middle frequency (from 20 to $30 \mathrm{~Hz}$ ), and (d) signal reconstruction at high frequency (from 40 to $50 \mathrm{~Hz}$ ). 
pulled down when the seismic waves propagate through the gas-saturated and water-saturated layers. Because of the physical property differences between the dry and gas or fluid saturated carbonate, the seismic reflections are different too. Layers (4), (7), and (8) have the same top and bottom boundaries (red dotted line); however, their seismograms are not able to display the same reflecting characteristics. Notably, the time delay for the gassy carbonate (green rectangular box) is much larger than the water filled carbonate (blue rectangular box). Furthermore, the seismic reflections of their top boundaries are not very distinct.

Figure $2 \mathrm{~b}$ shows the $5-10 \mathrm{~Hz}$ reconstructed seismogram. Obviously, at low frequency, the top seismic reflection of the dry carbonate (4) layer is the weakest among (4), (7), and (8) layers, but the bottom seismic reflection is inverted. When comparing seismic events, the former layer (7) has more energy than the latter layer (8). The boundaries of gassy and hydrous carbonates are very clear, in the rectangular box where strong energy groups are observed.

Figure $2 \mathrm{c}$ shows the $20-30 \mathrm{~Hz}$ reconstructed seismogram. At a middle frequency, the gas or fluid saturated carbonates contain weaker seismic reflection events than the other layers. In particular, the reflection energy of gassy carbonate is weakest among them.

Figure $2 \mathrm{~d}$ shows the $40-50 \mathrm{~Hz}$ reconstructed seismogram. It is well known that while the impedances change from high to low, the polarity of seismic events will be negative. As shown in Fig. 2d, at high frequency, the top troughs of layers (7) and (8) display the top boundaries clearly.

For a prime example with clear contrast, from Fig. 2a, we select the 30th, 55th, and 145th traces to decompose and reconstruct in the different frequency zone. The selected three traces are related with the seismogram of the dry, gas-saturated and fluid-saturated carbonates respectively. Figure 3a-c shows that nearly all of the events have increased strength correlating to increased frequency with the exception of the original. Figure $3 b$ shows that the top seismic reflections of the gassy carbonate become increasingly clear with increased frequency, while Fig. $3 \mathrm{c}$ shows this feature of the hydrous carbonate to be inferior.

Therefore, from the model testing results, we can draw the following conclusions:

u the low-frequency reconstructed seismogram highlights the reflecting energy of the reservoirs,

$\square$ the reflections of the gas-saturated and water-saturated carbonates are not strong in the middle-frequency reconstructed seismogram,

- the high-frequency reconstructed seismogram outlines the layer boundaries. 


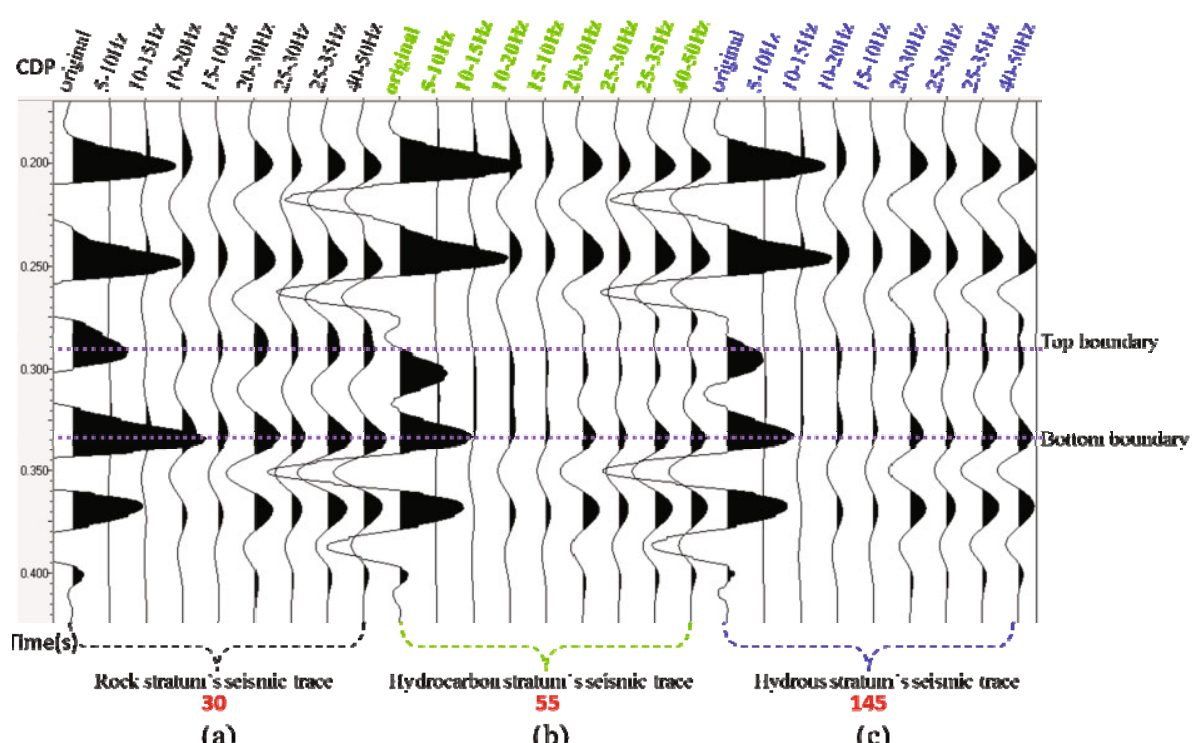

(a)

(b)

(c)

Fig. 3. Frequency-dependent seismic responses of the geological model: (a) reconstructed seismogram of the unfilled carbonate, (b) frequency-dependent seismogram of the carbonate filled with gas, and (c) frequency-dependent response of the carbonate filled with water.

\section{APPLICATION IN GAS RECOGNITION OF REEF RESERVOIR IN CHANGXING FORMATION OF YUANBA GAS FIELD}

\subsection{Sedimentary facies features}

Yuanba gas field is located in Sichuan Province in China, and is by far the most deeply buried marine gas field in China. Figure 4a shows the geographic location of Yuanba gas field. Changxing formation in Yuanba gas field is a representative formation combining reef and beach sedimentation. There are four sedimentary facies zones from northeast to southwest, namely continental shelf, slope, platform margin and open platform, respectively (Fig. 4b). In the early stage of Changxing's formation, the southeastern sections of the reservoir consisted of open bench terrace sediment, the northeast of the reservoir was slope and land shed sediment, and the landform was generally flat. The thin biodetritus beach and sandstone beach developed at parts of the open bench terrace. However, the reservoir was not productive and is under deep water. In these zones, there are only scattered high energy biodetritus beach reservoirs in locally high areas. In the medium term of Changxing's formation, the southwest portions gradually developed to a bench terrace edge, and produced thick, high energy biodetritus beach sediments which were widely distributed. In the later period of Changxing's 
(a)

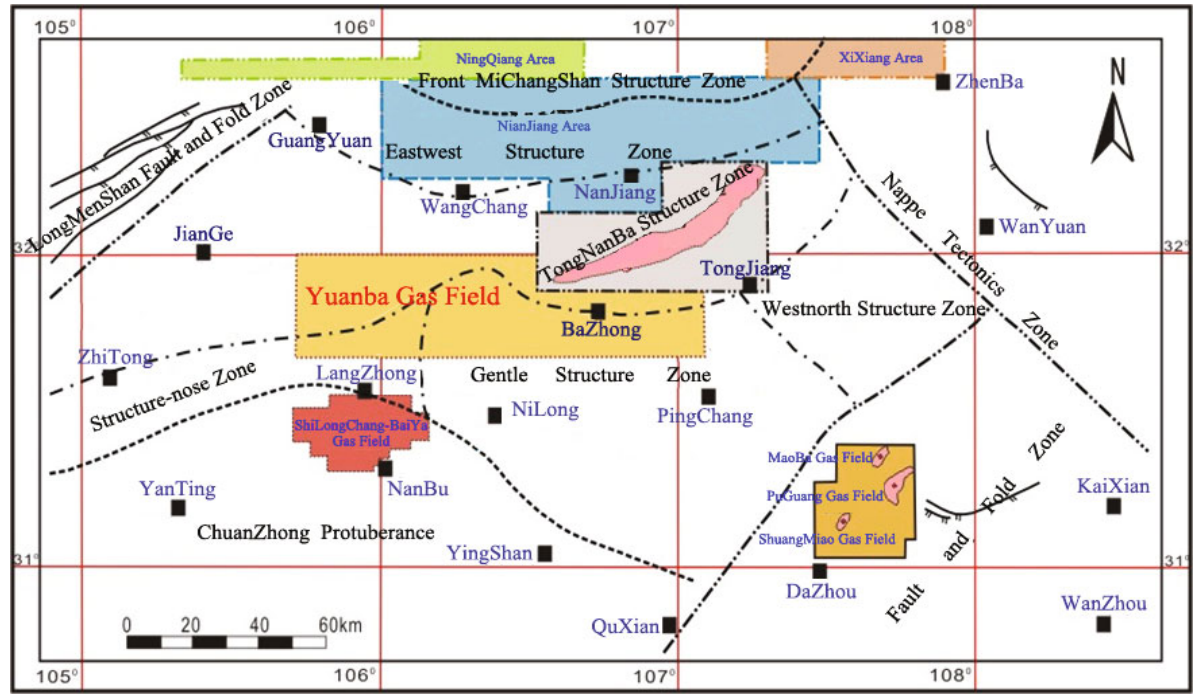

(b)

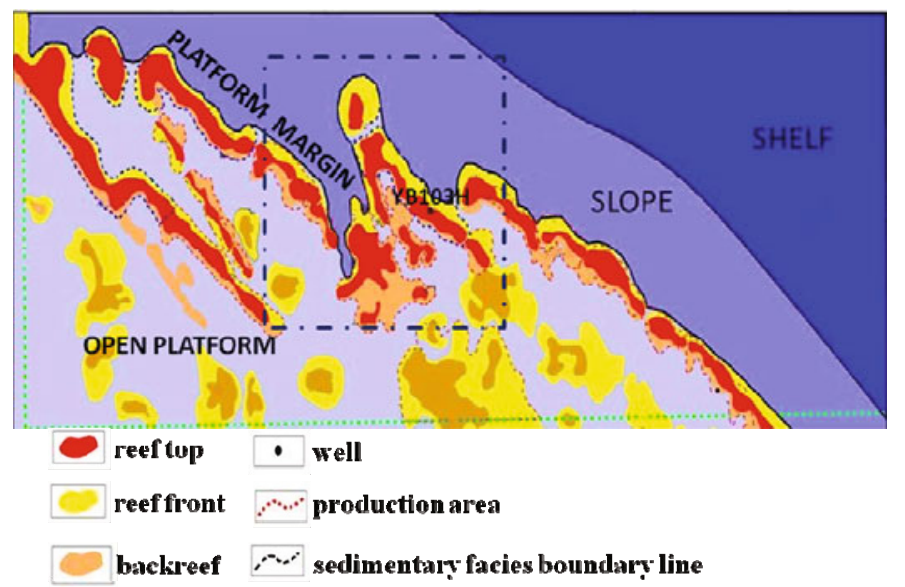

Fig. 4. The geographic location and the sedimentary facies of Yuanba gas field: (a) the geographic location of Yuanba gas field, and (b) the sedimentary facies of Yuanba gas field.

formation, the sediment topography changed greatly, and the organic reef began to develop at the margin of the continental shelf (Wang et al. 2012). The organic reefs in Changxing formation of Yuanba gas field mainly developed outside the bench terrace edge, and are distributed in a series of nonconnecting bands. With the reef rock filling constantly into the back, a shallow bench will be developed and mixed gradually in it. Therefore, the organic reef and the shallow bench sections offer the greatest potential reservoir zones above the Changxing formation. 


\subsection{Reservoir characteristics}

In Yuanba gas field, the Changxing formation consists of dolomite and limestone. Petrophysical properties of dolomite are more favorable for gas reserviors than those of limestone. Autoclastic dolomite and aplite dolomite are important rock types for reservoir strata. The reef reservoir is formed of dolomitic residue and non-residue autoclastic solution pores, organic clastic limestone, and organic reef limestone. The beach reservoir mainly consists of gray solution pore dolomite and gray matter as well as residue autoclastic limestone dolomite. It also has non-dolomitic gray limestones formed of autoclastic, sandclastic, and conglomerate clastic. Notably, solution pore dolomite is the most likely rock type to contain the largest gas reserves.

Statistics of core testing show that the porosity of Changxing formation reef reservoir is $0.23 \sim 19.59 \%$, with the average of $4.06 \%$, most of the values range between $2 \sim 5 \%$ (Fig. $5 \mathrm{a}$ ), the permeability is $0.0028 \sim$ $1720.7187 \times 10^{-3} \mu^{2}$, the main peak values are $0.01 \sim 0.1 \times 10^{-3} \mu \mathrm{m}^{2}, 39 \%$ of samples' permeabilities are smaller than $0.1 \times 10^{-3} 3 \mu \mathrm{m}^{2}, 44 \%$ of samples' permeabilities are $0.1 \sim 10 \times 10^{-3} \mu^{2}$ (Fig. $5 \mathrm{~b}$ ). The porosities of most limestones are $<5 \%$, but most of the permeabilities are $>1 \mathrm{mD}$, which indicates that the fractures are the most important gas-bearing spaces. Changxing formation generally belongs to pore reservoirs and fracture-pore reservoirs.
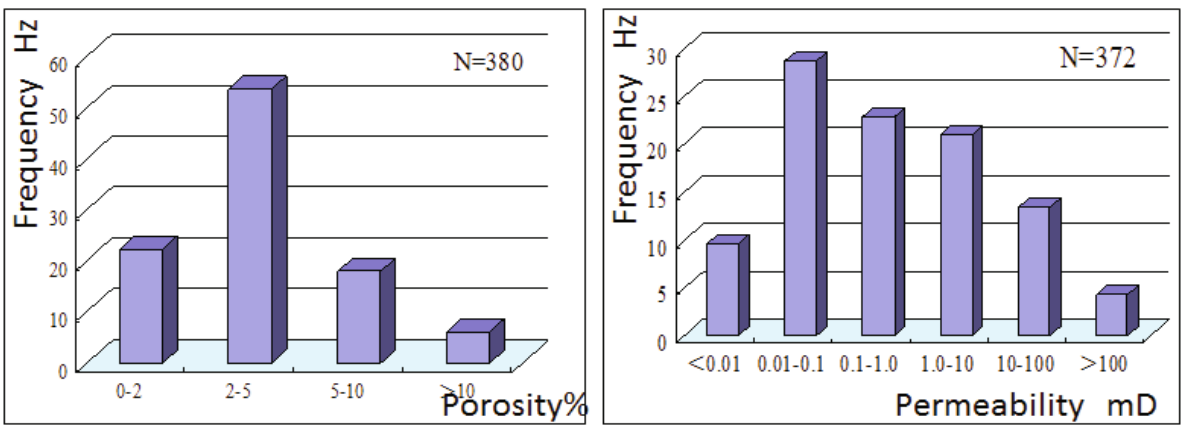

Fig. 5. The distributing histograms of organic reef reservoirs' physical property in Changxing formation of Yuanba gas field: (a) porosity, and (b) permeability. $N$ is the number of samples.

\subsection{Reef reservoir recognition}

The reef reservoir is a special kind of carbonate rock formation which has unique seismic reflecting characteristics in Yuanba gas field. On the outline of the reef body, the seismic response shows dome-shaped reflections. On the top of the reef, the seismic records appear to contain a "draping structure" within strong reflections. Seismic records internal to the reef present 
discontinuous, chaotic or nearly blank refections. On the reef bottom, the seismic records appear with low elevation reflection response. On the flanks of the reef, some onlap reflections can be clearly identified. All of these characteristics help us to identify the shape and edge of the reef, and accurately locate the position of reef reservoirs. However, according to the original sesimic data, it is difficult to deeply analyze the internal structures and growth periods of reefs because of the negative influences of discontinuated, irregular, flat or blank reflections from the inner reef. So, we applied seismic wavelet decomposition and reconstruction technology to process the original seismic data. It is expected to determine the seismic frequency response laws of the organic reef and allow insight into the intenal structure of the reef reservoir.

This paper shows a case study in part of Yuanba gas field which is shown in the blue rectangle in Fig. 4b. The study has focused on the well YB103H, in which open-flow capacity is $751.6 \times 104 \mathrm{~m}^{3} / \mathrm{d}$. From left to right, Fig. 6 shows the well $\operatorname{logs}$, the PSTM seismic data, and the reconstructed seismic data. In Figure $6 \mathrm{~b}$, c, and d, from top to bottom, the blue curves T-cx-5x, T-cx-3x, and T-cx-down represent the bottoms of different strata in the Changxing formation. Above the blue curve T-cx-5x, the first wave peak corresponds to the reef's top. The blue curve T-cx-3x shows the bottom of reef. The blue curve T-cx-down represents the bottom of the Changxing formation. The red arrow indicates mudstone strata overlying the reef. In the PSTM seismic data, the reflection events from the reef's outline is clear, but the reflection events from the overlying strata and the reef's interior are irregular and complex which makes the prediction and recognition of reef reservoirs extremely difficult. After decomposing the original seismic data, we reconstructed new seismic data with different dominant frequencies.

(a)

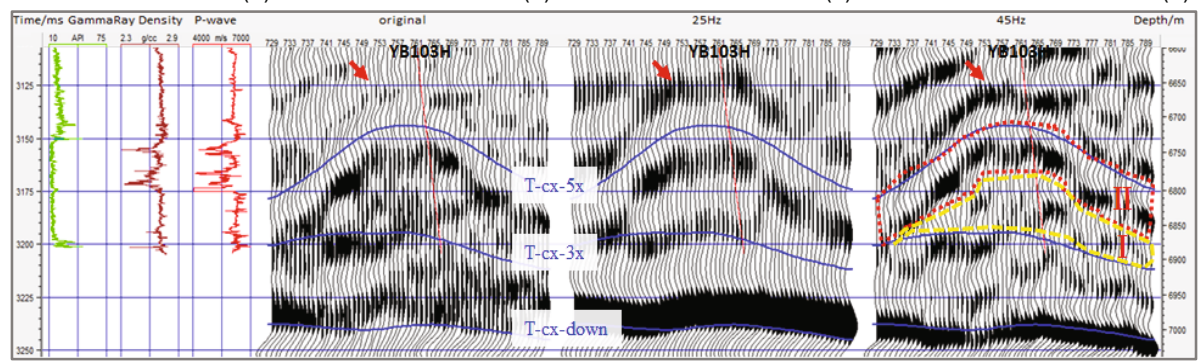

Fig. 6. Well seismic calibration and PSTM seismic data comparison with their reconstructed seismic data: (a) from left to right, well logs are natural gamma ray, density and acoustic logging curves respectively, (b) PSTM seismic data, (c) $25 \mathrm{~Hz}$ dominant frequency reconstructed seismic data, and (d) $45 \mathrm{~Hz}$ dominant frequency reconstructed seismic data. 


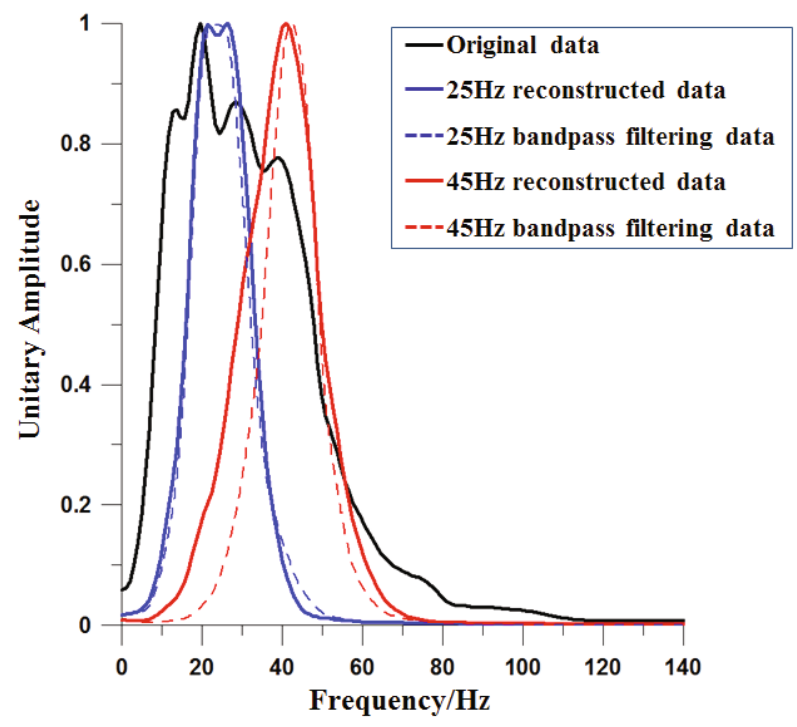

Fig. 7. The comparative amplitude spectrums of the original, bandpass filtering, and reconstructed seismic data.

The reconstructed seismic data with $25 \mathrm{~Hz}$ dominant frequency indicates that the mudstones covering and surrounding the reef are clearly identified. The reconstructed seismic data with $45 \mathrm{~Hz}$ dominant frequency, however, do not only clearly highlight the reflections from the reef's outline but also the internal evolution sequence. Figure $6 \mathrm{~d}$ shows two evolution ages of the reef which are enclosed by red and yellow frames, respectively. The reef developed from base to core and cap in one age, and evolved from core to cap in the other. Seismic reflections alone are not able to reveal the reef's internal characteristics any further; however, the main evolution periods can be identified from them when combined with well logs. Therefore, by comparing the three seismic data sets, the reconstructed seismic data is more utilizable not only to predict the reef reservoir, but also to help us combine the well to seismic calibration information to improve the recognition precision of the reef body.

Figure 7 shows the amplitude spectra of the original PSTM seismic data (dark line), the reconstructed seismic data with 25 and $45 \mathrm{~Hz}$ dominant frequency (blue and red lines, respectively), and the band pass filtering seismic data with 25 and $45 \mathrm{~Hz}$ center frequency (blue and red dash lines, respectively). By comparing the amplitude spectra of the reconstructed seismic data with that of the band pass filtering with the same frequency, both of frequency amplitude spectra are similar. Thus, the residual error of reconstructed data is negligible. 


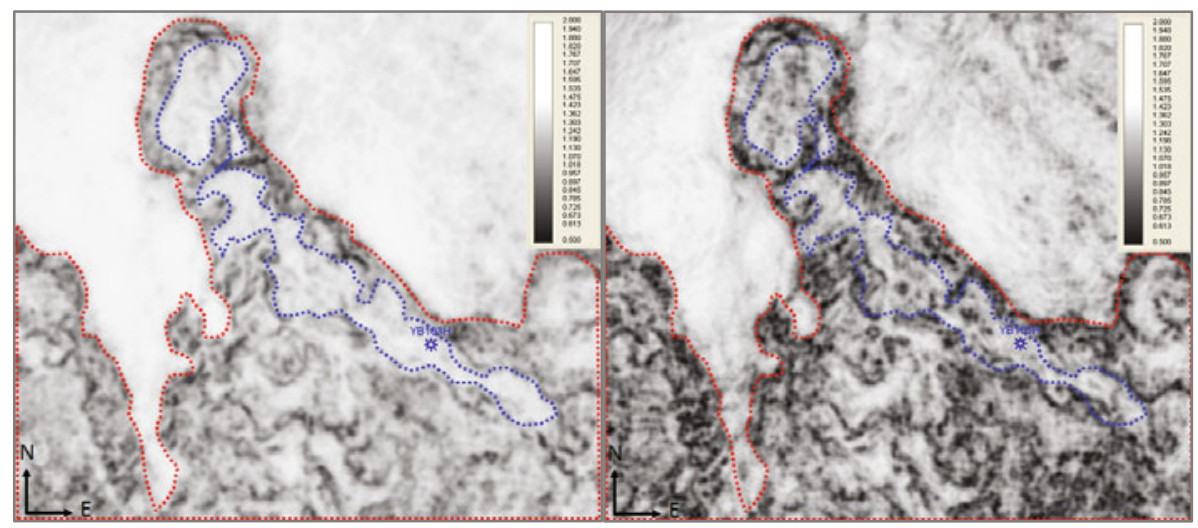

(a)

(b)

Fig. 8. Comparison of coherent attributes along T-cx-5x horizon between PSTM data and reconstructed PSTM data in Yuanba gas field: (a) coherence calculated by original seismic data, and (b) coherence calculated by $45 \mathrm{~Hz}$ dominant frequency reconstructed seismic data.

A seismic coherence attribute is usually used in fracture prediction. It is also useful for studying the reef-beach fracture-pore reservoirs in Changxing formation of Yuanba gas field. Figure 8 shows coherence attributes extracted from the original seismic data and the $45 \mathrm{~Hz}$ dominant frequency reconstructed seismic data on the T-cx-5x horizon in Yuanba gas field. Furthermore, the darker the color, the more probability of the developing fractures. On the T-cx-5x horizon in Changxing formation, the reservoir's spatial distribution can be highlighted by the coherence attributes which are circled by a red dotted line frame. However, when contrasting in Fig. 8 panels (a) with (b), it is evident that the latter has higher resolution than the former. In addition, in the area where the reef reservoir is circled by a blue dotted line frame, the abnormal coherence attribute of the latter is stronger than the former, and reveals the superior quality of the reef reservoir in which the coherence is poor and the probability of fracture growth higher.

In addition to coherence, the Root Mean Square (RMS) amplitude is another useful attribute to identify the reef. Figure 9 shows the RMS amplitudes of T-cx-5x horizon in Yuanba gas field. Figure 9a illustrates the RMS amplitudes calculated from the original seismic data and Fig. $9 \mathrm{~b}$ shows the RMS amplitudes calculated from the $45 \mathrm{~Hz}$ dominant frequent reconstructed seismic data. Inside the blue dotted line frame, the red areas are considered to be the reefs. By comparing panels (a) with (b), it is easy to see that the latter describes the spatial distribution of reef reservoir more clearly than the former. In the layout chart of the T-cx-5x horizon, the well YB103H in Yuanba gas field lies in the reservoir zone extending from northwest to 


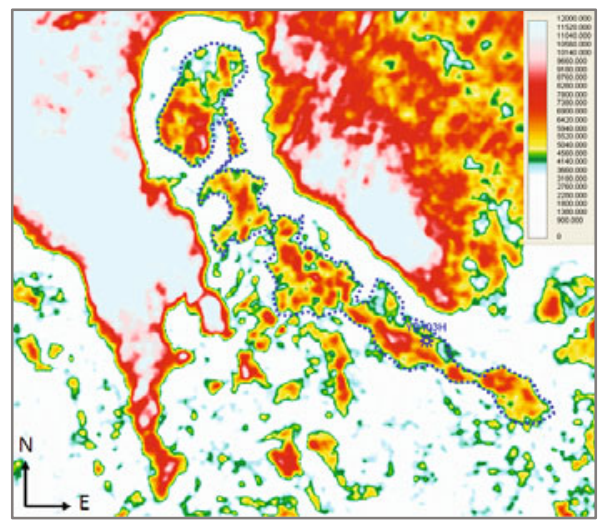

(a)

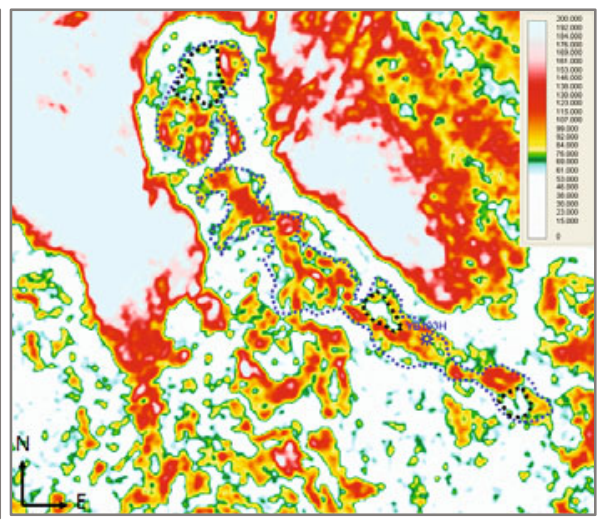

(b)

Fig. 9. Comparison of RMS amplitude attributes along the T-cx-5x horizon between PSTM seismic data and reconstructed seismic data in Yuanba gas field: (a) RMS amplitude calculated by original seismic data, and (b) RMS amplitude calculated by $45 \mathrm{~Hz}$ dominant frequency reconstructed seismic data.

southeast, having the same growth orientation as the reef zone. Although both, (a) and (b), can clearly describe the spatial distribution of a high quality reef reservoir, the latter can describe the inner boundary of the reef reservoir in more detail than the former, which is circled by the black dotted line frame.

Despite the reservoirs of Changxing formation in Yuanba gas field being very tight, the reef's porosity is relatively high, and its fractures are well developed, which is advantageous for hydrocarbon accumulation and migration. Notably, the reef reservoir has critical factors for spatial distribution of gas, reserves, and production. After comparing and analyzing the original and reconstructed seismic data, the results show that the reconstructed data can effectively highlight characteristics of seismic reflections within the reef reservoirs which allow in-depth analysis and understanding of their spatial distribution, internal structure, and evolution.

The RMS amplitude ratio of reconstructed data can also be applied to further understand the identified reef reservoirs. Figure 10 shows the RMS amplitude ratio of the 8 and $45 \mathrm{~Hz}$ reconstructed seismic data in Yuanba gas field, which can be used to distinguish between the strata consisting of gaswater or purely gas. In Figure 10, black shows the original seismic profile, and the red-yellow-green-white represents the RMS amplitude ratios from small to large. In the location of well YB103H, the reef reservoir top where fractures and pores grow well is mainly within the gassy strata (indicated by red arrows) which spread along the reef widely. The gas-water stratum is very narrow and lies in the bottom of reef cap showed in the white area be- 


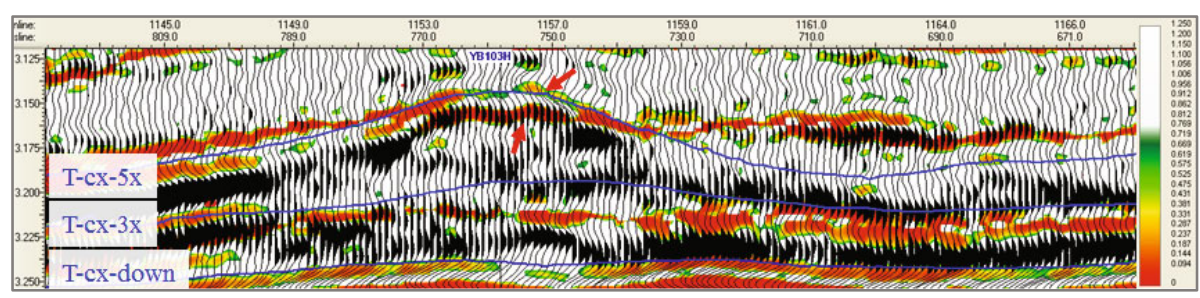

Fig. 10. Original seismic data and RMS amplitude ratio of 8 and $45 \mathrm{~Hz}$ reconstructed seismic data in Yuanba gas field.

tween red arrows. These results prove that the RMS amplitude ratio of reconstructed data is useful in solving the technical challenges of recognizing reef reservoirs' gas within the Changxing formation in Yuanba gas field.

To sum up, in Changxing formation, the gas prediction results based on the reconstructed data fit exactly with the logging results of well YB103H. Hence, the reconstructed data perform well for understanding the properties of the organic reef, and provide important evidence for highly productive reservoir prediction and gas recognition. Consequently, it is an extremely useful method in gas exploration and development.

\section{CONCLUSION}

In Changxing formation of Yuanba gas field, the applications of wavelet decomposition and reconstruction technology for reef reservoirs identification show that:

u the reconstructed seismic data of middle to high frequency (about $25 \mathrm{~Hz}$ ) can highlight the mudstone overlying the reef, and exactly describe the reef's outline;

$\square$ the reconstructed seismic data of high frequency (about $45 \mathrm{~Hz}$ ) can identify the reef's internal characteristics, such as the spatial distribution of the reef and in situ fracture development; these factors are paramount in order to recognize the reef's evolution history and predict the highly productive zones of the reservoir;

- by combining the low and high frequency reconstructed seismic data, we can effectively and efficiently determine spatial distribution of the gas reservoir.

In short, the wavelet decomposition and reconstruction technology can be successfully applied in reef reservoir prediction and gas recognition, proving that the technology is an extremely useful tool with promising potential applications to assist in future gas exploration and development. 
Acknowledgments. This work was partially supported by NSFC Project No. 41204071 and No. U1262206, the National High Technology Research and Development Program of China (No. 2013AA064201), application program of science and Technology Department of Sichuan province, China (No. 2013JY0060), and Cultivating programme of excellent innovation team of Chengdu University of Technology.

\section{References}

An, P. (2006), Application of multi-wavelet seismic trace decomposition and reconstruction to seismic data interpretation and reservoir characterization. In: Proc. 76th SEG Annual Meeting, 1-6 October 2006, New Orleans, USA, SEG-2006-0973.

Bakulin, A.V., and L.A. Molotkov (1998), Effective seismic models of fractured and porous media, St. Petersburg University Press, St. Petersburg (in Russian).

Bakulin, A., V. Grechka, and I. Tsvankin (2000), Estimation of fracture parameters from reflection seismic data-Part I:HTI model due to a single fracture set, Geophysics 65, 6, 1788-1802, DOI: 10.1190/1.1444863.

Battista, M.B., C. Knapp, T. McGee, and V. Goebel (2007), Application of the empirical mode decomposition and Hilbert-Huang transform to seismic reflection data, Geophysics 72, 2, 29-37, DOI: 10.1190/1.2437700.

Bi, C.C., L.X. Li, Y. Mei, Y.C. Zhang, and C. He (2007), Geological control factors of Changxing organic reef distribution and seismic prediction techniques, East Sichuan Basin, Nat. Gas. Geosci. 18, 4, 2-7.

Burnett, M.D., J.P. Castagna, E. Méndez-Hernández, G.Z. Rodríguez, L.F. García, J.T.M. Vázquez, M.T. Avilés, and R.V. Villaseñor (2003), Application of spectral decomposition to gas basins in Mexico, The Leading Edge 22, 11, 1130-1134, DOI: 10.1190/1.1634918.

Cai, X.Y. (2011), The subtly method of reservoir and exploration effects on the organic reef-beach body of Changxing Formation, Yuanba Area, Northeastern Sichuan, Eng. Sci. 13, 28-33 (in Chinese with English abstract).

Castagna, J.P., S.J. Sun, and R.W. Siegfried (2003), Instantaneous spectral analysis: Detection of low-frequency shadows associated with hydrocarbons, The Leading Edge 22, 2, 120-127, DOI: 10.1190/1.1559038.

Chen, Y. (2011), Prediction on reef reservoir in Changing group of Yuanba area, Northeast Sichuan Basin, Geophys. Prospect. Petrol. 50, 2, 173-180 (in Chinese).

Cohen, L. (1995), Time-frequency Analysis, Prentice Hall, Eaglewood Cliffs, 299 pp.

Farge, M. (1992), Wavelet transforms and their applications to turbulence, Ann. Rev. Fluid Mech. 24, 395-457, DOI: 10.1146/annurev.fl.24.010192.002143. 
Gao, J.H., W.B. Wang, and G.M. Zhu (1996), On the choice of wavelet functions for seismic data processing, Acta Geophys. Sinica 39, 3, 392-400 (in Chinese).

Goupillaud, P., A. Grossmann, and J. Morlet (1984), Cycle-octave and related transforms in seismic signal analysis, Geoexploration 23, 1, 85-102, DOI: 10.1016/0016-7142(84)90025-5.

Grubb, H.J., and A.T. Walden (1997), Characterizing seismic time series using the discrete wavelet transform, Geophys. Prospect. 45, 2, 183-205, DOI: 10.1046/ j.1365-2478.1997.00346.X.

Hu, W.G., Y. Pu, Z.N. Zhao, and J.L. Xiao (2010), Identification of reef reservoir of Changxing formation in Yuanba area of Northeastern Sichuan Basin, Geophys. Prospect. Petrol. 49, 1, 46-53 (in Chinese).

Hudson, J.A. (1980), Overall properties of a cracked solid, Math. Proc. Cambridge Philos. Soc. 88, 2, 371-384, DOI: 10.1017/S0305004100057674.

Hudson, J.A. (1981), Wave speeds and attenuation of elastic waves in material containing cracks, Geophys. J. Int. 64, 1, 133-150, DOI: 10.1111/j.1365246X.1981.tb02662.x.

Hudson, J.A. (1988), Seismic wave propagation through material containing partially saturated cracks, Geophys. J. Int. 92, 1, 33-37, DOI: 10.1111/j.1365246X.1988.tb01118.x.

Hudson, J.A., E.Liu, and S. Crampin (1996), The mechanical properties of materials with interconnected cracks and pores, Geophys. J. Int. 124, 1, 105-112, DOI: 10.1111/j.1365-246X.1996.tb06355.x.

Liu, J.L., and K.J. Marfurt (2005), Matching pursuit decomposition using Morlet wavelets. In: Proc. 75th SEG Annual Meeting, 6-11 November 2005, Houston, USA, SEG-2005-0786.

Lu, W.K., and F.Y. Li (2013), Seismic spectral decomposition using deconvolutive short-time Fourier transform spectrogram, Geophysics 78, 2, 43-51, DOI: 10.1190/geo2012-0125.1.

Ma, Y.S., C.L. Mou, Q.Y. Tan, Q. Yu, and R.H. Wang (2007), Reef-bank features and their constraint to reservoirs of natural gas, from Permian Changxing Formation to Triassic Feixianguan Formation in Daxian-Xuanhan Area of Sichuan Province, South China, Earth Sci. Front. 14, 1, 182-192, DOI: 10.1016/S1872-5791(07)60007-4.

Mallat, S.G., and Z. Zhang (1993), Matching pursuits with time-frequency dictionaries, IEEE Trans. Signal Process. 41, 12, 3397-3415, DOI: 10.1109/ 78.258082 .

Morlet, J., G. Arens, E. Fourgeau, and D. Giard (1982a), Wave propagation and sampling theory - Part I: Complex signal and scattering in multilayered media, Geophysics 47, 2, 203-221, DOI: 10.1190/1.1441328.

Morlet, J., G. Arens, E. Fourgeau, and D. Giard (1982b), Wave propagation and sampling theory - Part II: Sampling theory and complex waves, Geophysics 47, 2, 222-236, DOI: 10.1190/1.1441329. 
Partyka, G., J. Gridley, and J. Lopez (1999), Interpretational applications of spectral decomposition in reservoir characterization, The Leading Edge 18, 3, 353360, DOI: 10.1190/1.1438295.

Reine, C., M. van der Baan, and R. Clark (2009), The robustness of seismic attenuation measurements using fixed- and variable-window time-frequency transforms, Geophysics 74, 2, 123-135, DOI: 10.1190/ 1.3043726.

Sinha, S., P. Routh, and P. Anno (2009), Instantaneous spectral attributes using scales in continuous-wavelet transform, Geophysics 74, 2, 137-142, DOI: 10.1190/1.3054145.

Thomsen, L. (1986), Weak elastic anisotropy, Geophysics 51, 10, 1954-1966, DOI: 10.1190/1.1442051.

Thomsen, L. (1995), Elastic anisotropy due to aligned cracks in porous rock, Geophys. Prospect. 43, 6, 805-829, DOI: 10.1111/j.1365-2478.1995.tb00282.x.

Wang, Y.H. (2007), Seismic time-frequency spectral decomposition by matching pursuit, Geophysics 72, 1, 13-20, DOI: 10.1190/1.2387109.

Wang, Y.H. (2010), Multichannel matching pursuit for seismic trace decomposition, Geophysics 75, 4, 61-66, DOI: 10.1190/1.3462015.

Wang, Z.H., J. Deng, Q.Y. Tan, R.H. Wang., and J.X. Cheng (2012), Characteristics of typical sedimentary facies and their petrophysics of Changxing formation in Yuanba district, J. Mineral. Petrol. 32, 2, 86-96.

Xiong, X.J., Z.H. He, and D.J. Huang (2009), Numerical simulation on seismic response features of reef, Acta Petrolei Sin. 30, 1, 75-79 (in Chinese).

Xu, T.J., Z.M. Shen, and X.K. Wen (2010), Research and application of multi-wavelet decomposition and reconstructing technology, J. Chengdu Univ. Technol. (Sci. Technol. Ed.) 37, 6, 660-665.

Xu, T.J., B.J. Cheng, Z.P. Qian, J.M. Tang, Q.G. Gan, and Z.M. Shen (2011), Multiscale frequency and absorption attributes of seismic signals, J. Geophys. Eng. 8, 3, 457-463, DOI: 10.1088/1742-2132/8/3/006.

Xue, Y.J., J.X. Cao, and R.F. Tian (2013), A comparative study on hydrocarbon detection using three EMD-based time-frequency analysis methods, J. Appl. Geophys. 89, 108-115, DOI: 10.1016/j.jappgeo.2012.11.015.

Zhang, Q., and W.K. Lu (2010), Spectral decomposition using deconvolutive short time Fourier transform spectrogram. In: Proc. 80th SEG Annual Meeting, 1722 October 2010, Denver, USA, SEG-2010-1581.

Zhang, R.F. (2008), Spectral decomposition of seismic data with CWPT, The Leading Edge 27, 3, 326-329, DOI: 10.1190/1.2896622.

Received 8 October 2013

Received in revised form 6 August 2014

Accepted 21 October 2014 